J. Asiat. Soc. Bangladesh, Sci. 44(2): 195-210, December 2018

\title{
COMPARATIVE STUDY OF THE CHANGES IN CLIMATIC CONDITION AND SEASONAL DROUGHT IN NORTH-WESTERN PART OF BANGLADESH
}

\author{
RIAZ HOSSAIN KHAN ${ }^{1}$ AND MOHAMMAD SAIFUL ISLAM ${ }^{2 *}$ \\ ${ }^{I}$ Department of Environmental Science, Patuakhali Science and Technology University, \\ Bangladesh \\ ${ }^{2}$ Department of Geology, University of Dhaka, Dhaka-1000, Bangladesh
}

\begin{abstract}
The study examines the long-term and seasonal climatic variations in north-western part of Bangladesh (NWPB). Long-term variation of different climatic parameters reveals that significant increases in temperature are associated with decreasing evaporation which could be attributed to wind speed variation and seasonal variation of temperature. Increase of monsoon rainfall during monsoon period and scarcity or absence of rainfall during dry periods increase the region's vulnerability to monsoon flood and seasonal drought, respectively. The area witnesses a single peak of rainfall in July during the first half of the study period (1964-1985), whereas the same experiences bimodal peak of rainfall during July and September in the second half of the study period (1986-2007). This may signify the changes of climatic condition in the studied area. Annual variability of rainfall as well as the unpredictable shifting of rainfall periods might be a possible reason for the seasonal drought. The aridity index indicates that the overall dryness of the area has increased during winter season. The study shows that humidity increases at all stations throughout the year. The study also shows that long-term seasonal variation of both surface and groundwater level is also prominent. Gradual decrease of surface water level was observed in Teesta River which might be due to unilateral withdrawal of surface water in the upper riparian. Detailed investigation on hydrometeorology of the study area is required to see whether there is any trend of climate change in the area.
\end{abstract}

Key words: Aridity index, Climate change, Hydrometeorology, Seasonal drought, Monsoon flood

\section{Introduction}

Geographically Bangladesh extends from $20^{\circ} 34^{\prime} \mathrm{N}$ to $26^{\circ} 38^{\prime} \mathrm{N}$ and $88^{\circ} 10^{\prime} \mathrm{E}$ to $92^{\circ} 41^{\prime} \mathrm{E}$ latitude and longitude, respectively. Climatically the country belongs to sub-tropical region where monsoon weather prevails throughout the year. Three distinct seasons can be recognized in Bangladesh from climatic point of view: (i) The dry winter season from November to February, (ii) the pre-monsoon hot summer season from March to May, and (iii) the rainy monsoon season which lasts from June to October (Rashid 1991).

*Author for correspondence: Email: msaiful@du.ac.bd 
Bangladesh is one of the most disaster-prone countries in the world. High spatial and temporal climatic variability, extreme weather events, high population density, high incidence of poverty and social inequity, poor institutional capacity, inadequate financial resources, and poor infrastructure have made Bangladesh highly vulnerable to disaster (Ahmed and Kim 2003).

The average temperature of Bangladesh ranges from 17 to $20.6^{\circ} \mathrm{C}$ during winter and 26.9 to $31.1^{\circ} \mathrm{C}$ during summer. The average annual rainfall of the country varies from 1,329 $\mathrm{mm}$ in the northwest to $4,338 \mathrm{~mm}$ in the northeast (Shahid et al. 2005). The gradient of rainfall from west to east is approximately $9 \mathrm{~mm} / \mathrm{km}$. The western part of Bangladesh experiences an average areal rainfall of approximately $2,044 \mathrm{~mm}$, which is much lower than that of other parts of the country. The rainfall is also very much seasonal, almost $77 \%$ of rainfall occurs during monsoon. Like high annual variability of rainfall, temperature also fluctuates intensely in the country. In summer, the hottest days experience temperatures of about $45^{\circ} \mathrm{C}$ or even more in the region. Again in the winter the temperature even falls at $5^{\circ} \mathrm{C}$ in some places. Hence, the region experiences the two extremities that clearly contrast with the climatic condition of rest of the country (Banglapedia 2003).

Drought is a prolonged, continuous period of dry weather along with abnormal insufficient rainfall. It occurs when evaporation and transpiration exceed the amount of precipitation for a reasonable period. Drought causes the earth to dry up and a considerable hydrologic imbalance resulting water shortages, wells to dry, depletion of groundwater and soil moisture, stream flow reduction, crops to wither leading to crop failure and scarcity in fodder for livestock. In the context of global warming, most of the climatic models project a decrease in precipitation in dry season and an increase during monsoon in south Asia (Christensen et al. 2007).

The study area is located in the north-western part of Bangladesh and extends from $23^{\circ}$ $80^{\prime}$ to $26^{\circ} 38^{\prime} \mathrm{N}$ latitude and from $88^{\circ} 01^{\prime}$ to $89^{\circ} 70^{\prime} \mathrm{E}$ longitude (Fig. 1). The climate of the study area i.e., the NWPB is dominated by tropical monsoons. It is characterized by high temperature, moderate rainfall with often excessive humidity and fairly marked seasonal variations. The most striking feature of this climate is the reversal of the wind circulation between winter and rainy season, which is an integral part of the circulation system of the Indian subcontinent (Rashid 1991). Drought has become a recurrent natural phenomenon of NWPB in recent decades.

Prime objectives of the study were to determine the long term and seasonal changing patterns of various hydrometeorological parameters with time. The partial influences of 
changing climatic condition and human intervention for the recurrent drought and flood in the study area were also emphasized.
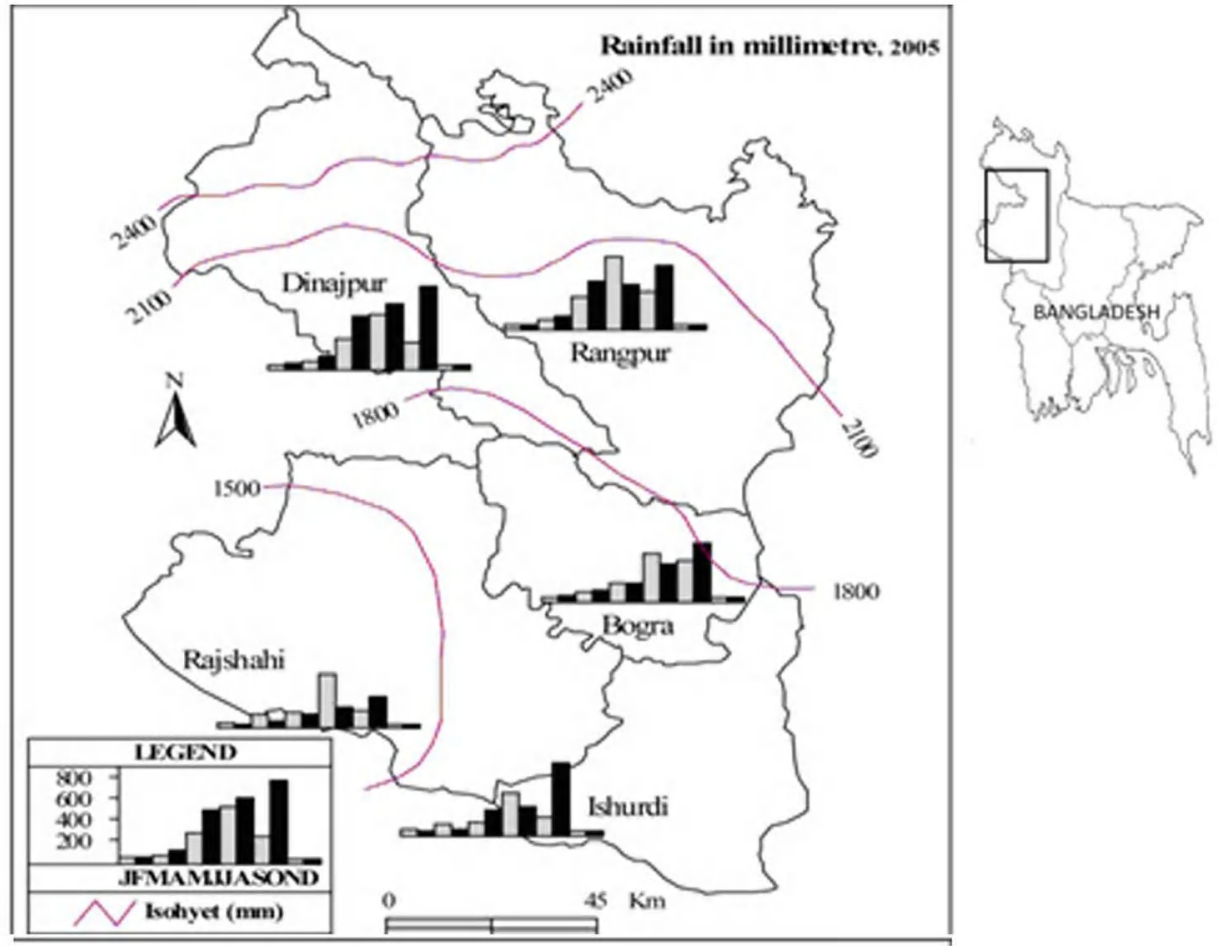

Fig 1. Relative location of the stations and the rainfall distribution map in the study area (Modified after Shamsuzzoha et al. 2011).

\section{Materials and Methods}

Time series data of available hydrometeorological parameters were collected and simple mean (M) was used for this work. Data of mean wind speed, humidity, temperature, rainfall were divided into two halves (1964 - 1985 and 1986 - 2007) in all stations to determine and compare the long term seasonal variation. The periods ranging from the years 1964 to 1985 and 1986 to 2007 hereinafter are referred to as first half and second half, respectively. Data of temperature and rainfall during winter, monsoon and summer were prepared to determine the long-term seasonal variation with time. Data for evaporation, surface water level (SWL) and groundwater level (GWL) were analyzed at selected time intervals (1968 - 1972, 2003 - 2007), (1995 - 2004) and (1995 - 2004), 
respectively. Aridity index (AI) curves were prepared to determine the variation of dryness at two selected intervals. Hydrographs from selected rivers were prepared to determine the long-term variation of SWL. Mean maximum and minimum SWL and GWL were measured at two intervals $(1995$ - 1999, 2000 - 2004) to understand the change of water level at different locations with time. GWL data were collected from nine observation wells and hydrographs were prepared to determine the GWL fluctuation at different locations. At last all of these parameters were correlated to understand the long term change in climatic condition of the study area. All hydrometeorological data were procured from Bangladesh Meteorological Department (BMD) and Bangladesh Water Development Board (BWDB).

\section{Results and Discussion}

Temperatures: Significant differences in seasonal temperature occur across the NWPB which is influenced by latitude and monsoon activities (Brammer 1996). Mean minimum temperature increases throughout the year at all stations. On the other hand, summer and winter mean maximum temperature decreases except at Ishurdi and Bogra. The highest increase of both mean maximum and minimum temperatures were found during monsoon. Both mean maximum and minimum temperatures at all stations during monsoon period were found higher than the previous years.

Most significant increase was observed at Bogra which rose from 34.67 to $35.52^{\circ} \mathrm{C}$. Highest temperature was found about $35.67^{\circ} \mathrm{C}$ at Rajshahi during the period of 1986 2007. The lowest monsoon temperature was found at Rangpur which was about $22.17^{\circ} \mathrm{C}$ during the second half. The fluctuation between the summer mean maximum and minimum temperature decreased during the year range of 1986 - 2007 compared to that during the period 1964 - 1985. The mean maximum temperature at all the stations decreased during summer except that at Ishurdi. The highest summer temperature increased up to $40.2^{\circ} \mathrm{C}$ at Ishurdi and the lowest summer temperature was found at Rangpur which was $16.44^{\circ} \mathrm{C}$ during the second interval. No significant fluctuation of mean winter temperature was observed at all stations. Highest winter temperature was found at Bogra which was about $30.49^{\circ} \mathrm{C}$ and the lowest was found about $9.36^{\circ} \mathrm{C}$ at Ishurdi (Table 1).

Wind: Wind in NWPB generally shows nearly the opposite direction of movement due to the differential heating and cooling of landmass and oceans during summer and winter. During the monsoon, a center of low pressure and monsoon trough develops over the west-central part of India because of intense surface heat. To replenish the low air 
pressure zone air containing high water vapor moves from the southern sea i.e. the Bay of Bengal which takes its route along the studied area. On the other hand, the high Himalayan mountain acts as an effective barrier for the airflow during winter period. Air subsiding beneath westerly jet stream (southern) causes subtropical high pressure and gives dry out-blowing over the studied area towards south which is mostly devoid of water vapor (Trewartha 1968). Pre-monsoon summer and autumn are the transition season which is characterized by lighter wind speed and more complicated flow patterns (Islam 2003).

Table 1. Mean maximum (Max) and minimum (Min) temperature at selected stations during monsoon, summer and winter period in the studied area.

\begin{tabular}{|c|c|c|c|c|c|c|c|c|c|c|c|c|}
\hline \multirow{3}{*}{ Location } & \multicolumn{4}{|c|}{ Monsoon temperature $\left({ }^{\circ} \mathrm{C}\right)$} & \multicolumn{4}{|c|}{ Summer temperature $\left({ }^{\circ} \mathrm{C}\right)$} & \multicolumn{4}{|c|}{ Winter temperature $\left({ }^{\circ} \mathrm{C}\right)$} \\
\hline & \multicolumn{2}{|c|}{ 1964-1985 } & \multicolumn{2}{|c|}{ 1986-2007 } & \multicolumn{2}{|c|}{ 1964-1985 } & \multicolumn{2}{|c|}{ 1986-2007 } & \multicolumn{2}{|c|}{ 1964-1985 } & \multicolumn{2}{|c|}{ 1986-2007 } \\
\hline & Max & Min & Max & Min & Max & Min & Max & Min & Max & Min & Max & Min \\
\hline Bogra & 34.67 & 22.27 & 35.52 & 22.77 & 38.26 & 16.96 & 37.14 & 17.67 & 30.23 & 10.15 & 30.49 & 10.9 \\
\hline Dinajpur & 35.04 & 22.28 & 35.26 & 22.78 & 37.95 & 16.95 & 36.97 & 17.67 & 29.26 & 10.09 & 29.18 & 10.93 \\
\hline Ishurdi & 35.16 & 21.75 & 35.37 & 22.52 & 37.3 & 19.4 & 40.2 & 21.2 & 30.16 & 8.52 & 30.19 & 9.36 \\
\hline Rajshahi & 35.45 & 22.19 & 35.67 & 22.53 & 39.71 & 16.82 & 39.5 & 16.72 & 30.22 & 9.95 & 30.12 & 9.37 \\
\hline Rangpur & 34.9 & 22.02 & 35.01 & 22.17 & 36.57 & 15.7 & 35.76 & 16.44 & 28.72 & 9.75 & 28.79 & 10.15 \\
\hline
\end{tabular}

Source: BMD.

Mean wind speed at Ishurdi, Dinajpur and Rajshahi decreased but it was increasing at Bogra and Rangpur during second half (1986 - 2007). During the first period (1964 1985), mean maximum wind speed was observed at Ishurdi which ranged from 5.37 to 7.48 knots. However, during the second period (1986 - 2007) the wind speed at Ishurdi was significantly lower than the past. The highest wind speed of about 4.76 knots was observed in April during the second half of the study period at Rangpur (Fig. 2).

Rainfall: Amount of precipitation in north-western Bangladesh shows spatial and seasonal variation. In the studied area the highest mean annual rainfall was recorded about $2338 \mathrm{~mm}$ at Rangpur. On the other hand, Dinajpur, Bogra, Ishurdi and Rajshahi experienced 2083, 1844, 1688 and $1465 \mathrm{~mm}$ of rainfall, respectively. From this observation it can be assumed that the amount of rainfall is gradually decreasing from the $\mathrm{N}-\mathrm{E}$ to the S-W part of the studied area which is more or less controlled by the geographical location of the area based on the proximity of the Himalayan.

The variations of mean annual rainfall at successive years are prominent in the studied area. The amount of precipitation in different years varied between 1758 and 2877, 1427 and 2969, 1431 and $2243 \mathrm{~mm}, 1184$ and 2097 and 1161 and $1806 \mathrm{~mm}$ at Rangpur, 
Dinajpur, Bogra, Ishurdi and Rajshahi, respectively without following any definite increasing or decreasing trend during the period from 1965 to 2007. The upward and downward shifting of the amount of rainfall is given in Table 2 (Shamsuzzoha et al. 2011).
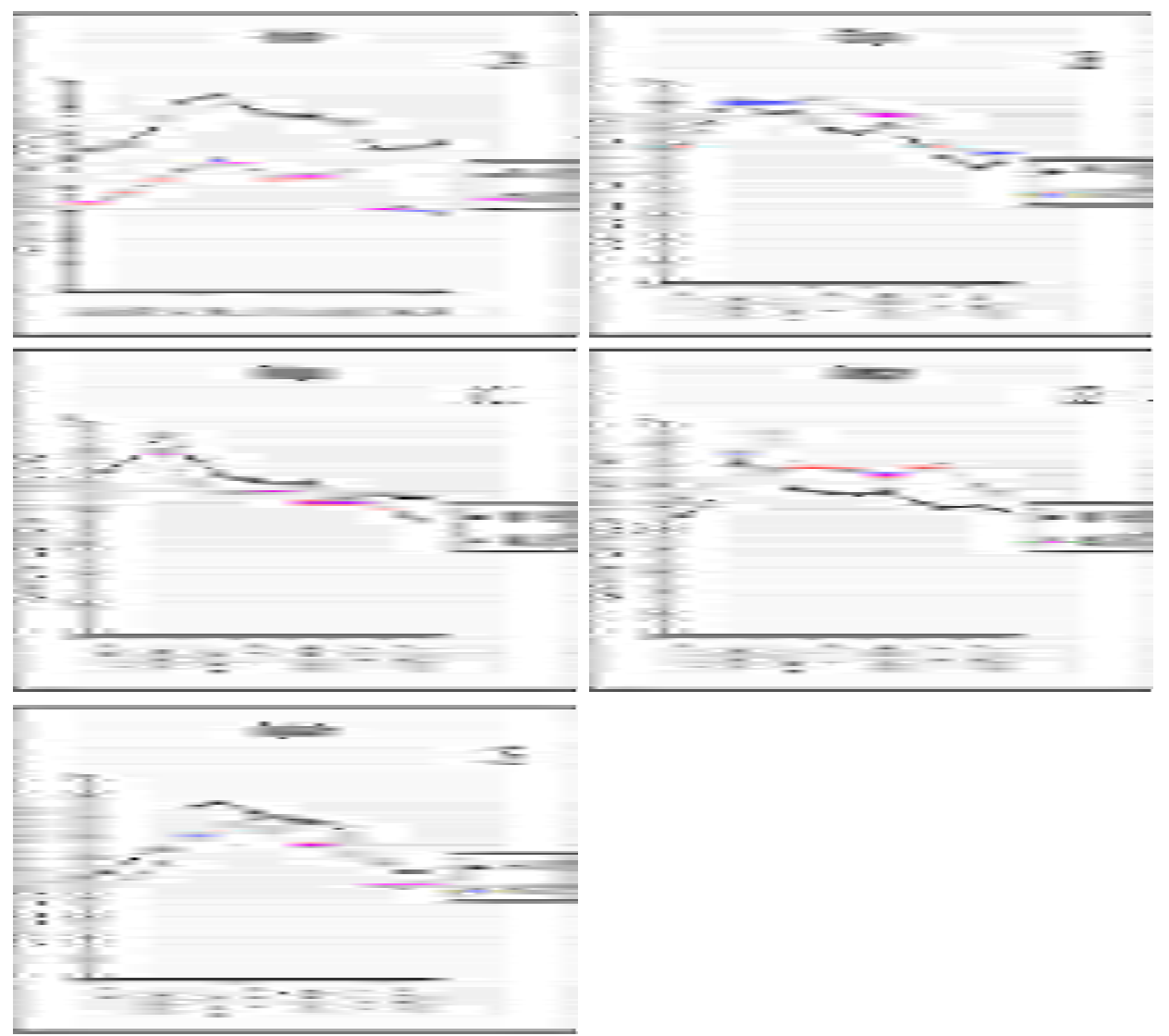

Fig. 2. Changes of mean monthly wind speed in the studied area - 2A: Ishurdi; 2B: Bogra;

2C: Dinajpur; 2D: Rangpur and 2E: Rajshahi.

At all the stations the maximum peak distribution of rainfall were observed at July both in 1964 - 1985 and in 1986 - 2007. Long-term seasonal changes in rainfall show that rainfall increased in most of the stations during the period between 1986 and 2007 compared to the first time interval especially during monsoon. Exception was observed at Ishurdi, which shows the opposite result during the months between April and August (Fig. 3). One important observation was that during the first half the pattern of rainfall exhibits unimodal peak which was found in July at all the stations but during the second 
half pattern of rainfall shows bimodal peak distribution. During the second interval, the first peak was found in July and another one in September with comparatively lower values. In Ishurdi the two rainfall peaks were almost equal. These evidences of the changing trend of rainfall pattern might be considered as a precursor for the shifting of rainfall peak seasons.

Table 2. Variation (Var.) of mean annual rainfall $(\mathrm{mm})$ and their percentage.

\begin{tabular}{|c|c|c|c|c|c|c|c|c|c|c|}
\hline \multirow[t]{2}{*}{ Year } & \multicolumn{2}{|c|}{ Bogra (1847) } & \multicolumn{2}{|c|}{ Dinajpur (2089) } & \multicolumn{2}{|c|}{ Rajshahi (1461) } & \multicolumn{2}{|c|}{ Rangpur (2333) } & \multicolumn{2}{|c|}{ Ishwardi (1681) } \\
\hline & Var. & $\%$ & Var. & $\%$ & Var. & $\%$ & Var. & $\%$ & Var. & $\%$ \\
\hline 1970 & $\downarrow 087$ & 4.67 & $\downarrow 668$ & 31.90 & $\downarrow 085$ & 5.76 & $\downarrow 336$ & 14.37 & $\uparrow 130$ & 7.68 \\
\hline 1975 & $\downarrow 42$ & 22.49 & $\downarrow 040$ & 1.89 & $\downarrow 305$ & 21.00 & $\downarrow 568$ & 24.27 & $\downarrow 177$ & 10.48 \\
\hline 1980 & $\downarrow 22$ & 11.8 & $\downarrow 128$ & 6.17 & $\uparrow 116$ & 7.88 & $\downarrow 211$ & 9.12 & $\downarrow 227$ & 13.39 \\
\hline 1985 & $\downarrow 14$ & 7.6 & $\uparrow 006$ & 0.25 & $\downarrow 210$ & 14.49 & $\uparrow 540$ & 23.11 & $\uparrow 097$ & 5.82 \\
\hline 1990 & $\uparrow 236$ & 12.71 & $\downarrow 010$ & 0.44 & $\uparrow 342$ & 23.51 & $\uparrow 155$ & 6.65 & $\uparrow 411$ & 24.39 \\
\hline 1995 & $\uparrow 403$ & 21.75 & $\uparrow 522$ & 24.90 & $\downarrow 028$ & 1.97 & $\uparrow 477$ & 20.49 & $\downarrow 498$ & 29.69 \\
\hline 2000 & $\downarrow 019$ & 0.94 & $\downarrow 566$ & 27.07 & $\uparrow 231$ & 15.69 & $\downarrow 579$ & 24.76 & $\uparrow 128$ & 7.57 \\
\hline 2005 & $\uparrow 245$ & 13.24 & $\uparrow 887$ & 42.42 & $\downarrow 057$ & 3.84 & $\uparrow 522$ & 22.30 & $\uparrow 139$ & 8.22 \\
\hline
\end{tabular}

$\downarrow$ Rainfall decrease, $\uparrow$ Rainfall increase. $\quad$ Source: Shamsuzzoha et al. 2011.

Comparatively higher rainfall during the monsoon period might aggravate the intensity of monsoon flood in the studied area. On the other hand, relative decrease in rainfall during dry period along with shifting of higher rainfall period and the uneven distribution of total annual rainfall in different years might increase the possibility of seasonal drought in the studied area.

Evaporation: In general, sunshine duration in Bangladesh is decreasing at an alarming rate. The overall annual decrease for the entire Bangladesh is about 0.36 hours a day in every 10 years. In general, evaporation rate during winter was comparatively lower than the rest of the months at all of the stations. Significant lowering of evaporation rate was observed at Dinajpur and Rajshahi but in Rangpur evaporation slightly increased during winter compared to the past (Fig. 4). Higher reduction of mean evaporation rate at Dinajpur and Rajshahi might be correlated with lower wind speed and decrease of mean maximum temperature at those two regions. Both maximum and minimum winter season temperature slightly increased in Rangpur which was not singly sufficient to explain the increasing amount of evaporation rate. Here, the variation of wind speed along with temperature might play a vital role for the variation of evaporation rate in all of these 
three areas. The reduction of sunshine duration can also be ascribed as one of the principal reasons for such a decrease in evaporation (IWFM 2009).

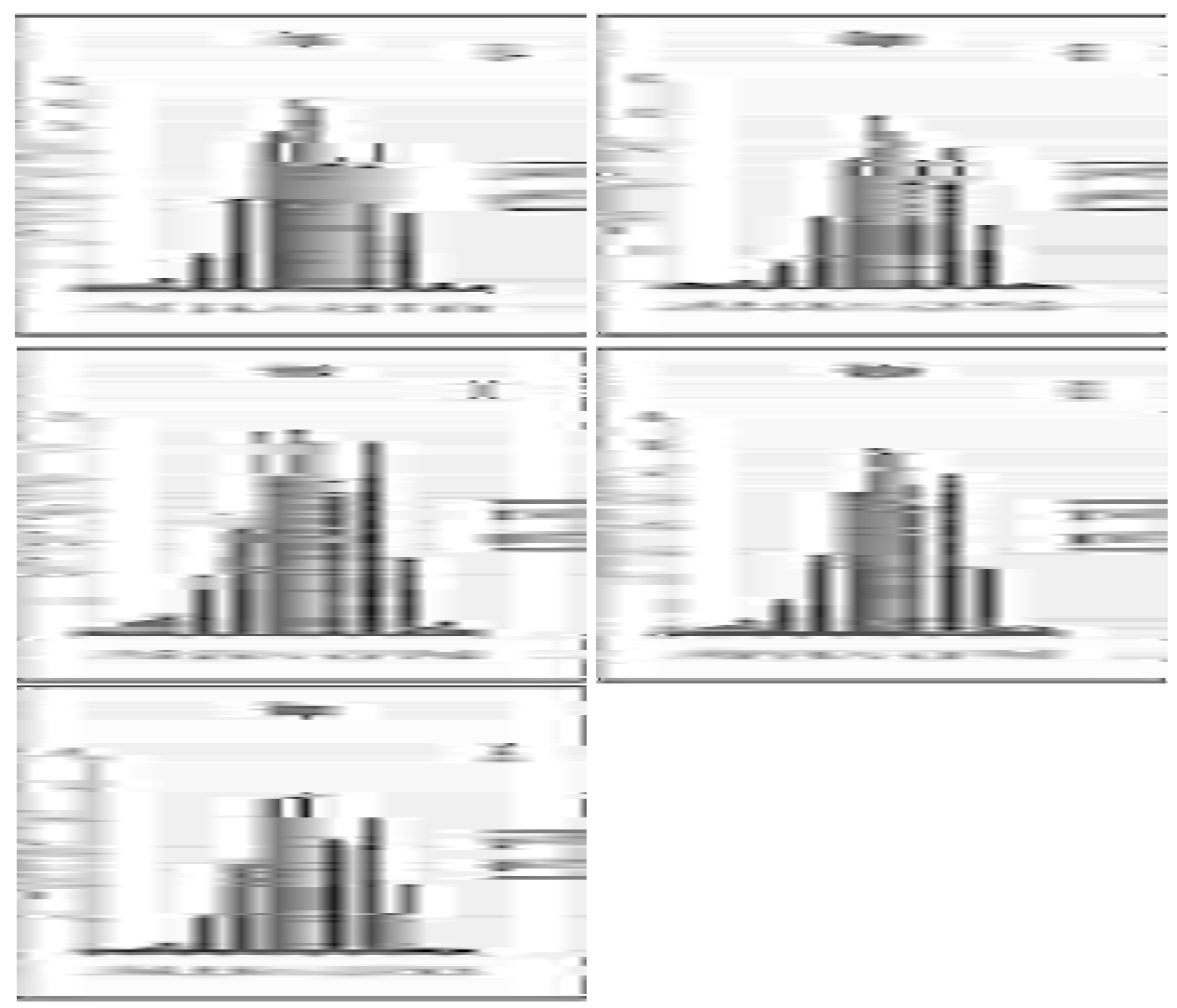

Fig. 3. Changes of mean monthly rainfall in the studied area - 3A: Bogra; 3B: Dinajpur;

3C: Ishurdi; 3D: Rajshahi and 3E: Rangpur.

Values of mean monthly evaporation during 1968 - 1972 varied between 48.65 and $147.17 \mathrm{~mm}, 34.02$ and $121.66 \mathrm{~mm}$, and 58.65 and $168.8 \mathrm{~mm}$ at Dinajpur, Rangpur and Rajshahi, respectively. During the period 2003 - 2007, the values ranged between 32 and $109.02 \mathrm{~mm}, 59.37$ and $101.58 \mathrm{~mm}$, and 38.38 and $98.01 \mathrm{~mm}$, respectively.

Aridity index (AI): Aridity Index (AI) can be used to demarcate the dry and wet periods and also to estimate the intensity of dryness and wetness of an area. AI values below 0.5 signify potential evaporation is two times the rainfall (McIntosh 1972) indicating a region of dry climate and vice versa. Values of AI at all of the measured stations were below 0.5 in winter and exceeded this limit during the rest of the months. Wet condition increased 
significantly during July in all of the regions but the difference declined during August. In Rangpur, the dryness significantly increased during August compared to the past years and also during the winter.
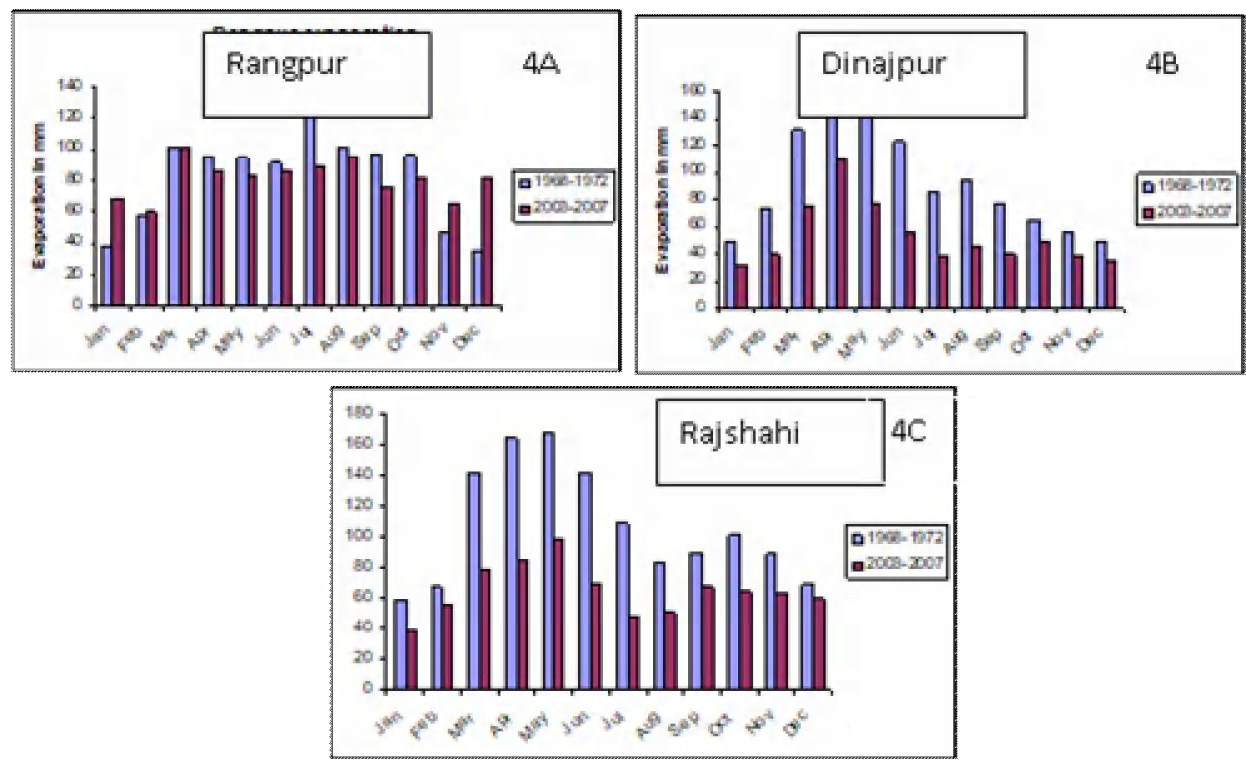

Fig. 4. Changes in mean monthly evaporation in the studied area - 4A: Rangpur; 4B: Dinajpur; 4C: Rajshahi.

In Dinajpur, AI value ranged between 0 and 6.19 during the period of $1968-1972$ whereas the value ranged between 0.17 and 11.96 during 2003 - 2007. At Rangpur, AI value ranges from 0.01 to 3.93 during the period of 1968 - 1972 and 0.06 to 6.26 during 2003 - 2007. Comparison of AI values in both of the regions showed that the value slightly reduced in winter especially during November to January. The value increased during the rest of the months. Most significant increase in AI value was found during monsoon. At Rajshahi, AI value was found between 0 and 3.44 during the period of 1968 - 1972 whereas the value ranges between 0.04 and 14.51 during $2003-2007$. The value increased throughout the year except winter. Significant increase in AI value was found during monsoon. Here, the highest AI value of about 14.51 was found at Rajshahi which indicated the higher possibility of flood in that area (Fig. 5).

Comparison of the second half with the first interval showed that the dryness of the area increased during the winter. Significant increase of AI value during monsoon represents the higher possibility of flood during those months. 
Humidity: In general, highest values of humidity were observed during monsoon period. During the period of 1964 - 1985 mean annual humidity in the studied area varied between the lowest 872 at Isurdi and the highest 962 at Rangpur. On the other hand, humidity increased up to 969 at Rangpur and 931 at Isurdi and Dinajpur during 1986 2007. During the second interval total mean annual humidity increased at all of the stations. The highest increase was found at Isurdi and the lowest at Rangpur (Fig. 6).

Comparison between the variations of humidity of the two intervals showed that the mean monthly humidity increased remarkably at most of the stations throughout the year but relatively lower increases were found during monsoon. In winter, relative increase in humidity higher than the past might be related to the higher evaporation rate during winter season in the second half.

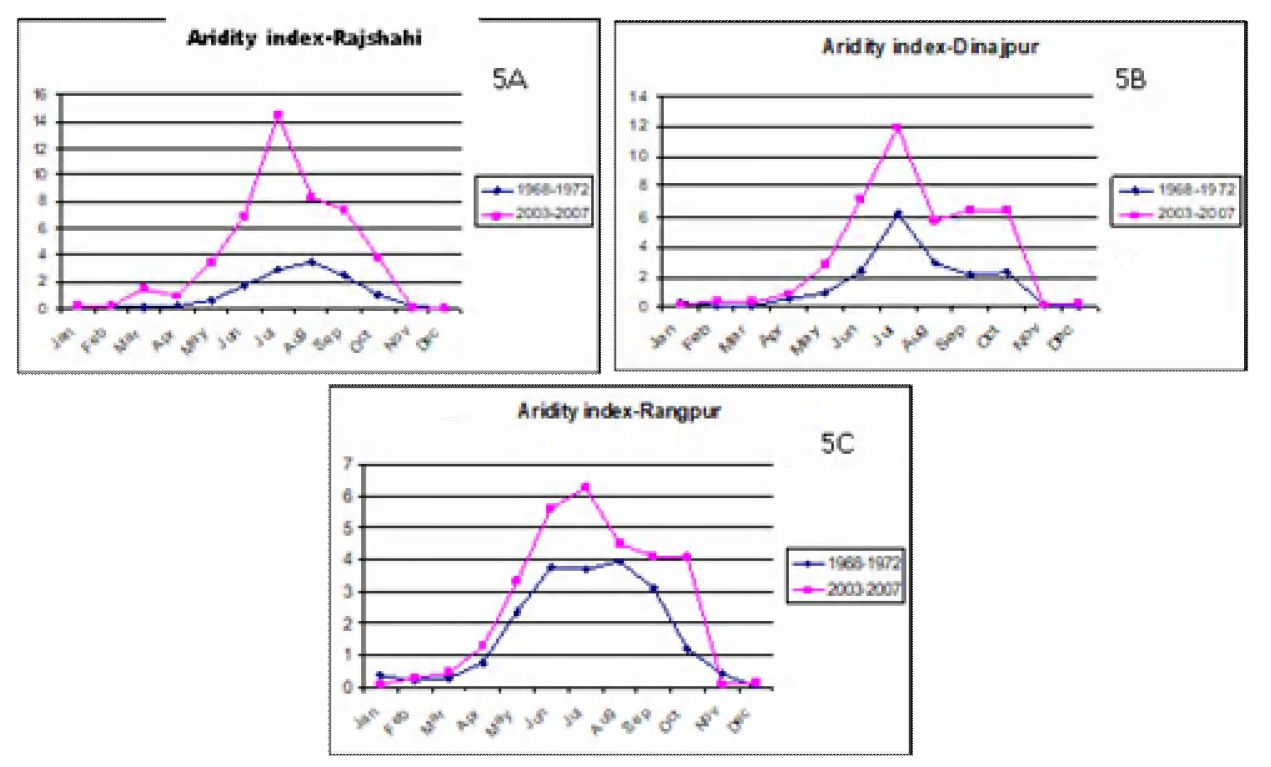

Fig. 5. Aridity Index (AI) curves at selected locations in the studied area - 5A: Rangpur; 5B: Dinajpur; 5C: Rajshahi.

Surface water level ( $S W L$ ): Construction of dam and significant withdrawal of water at the upstream regions affect the natural flow of transboundary rivers in the NWPB which create scarcity of surface water. It also tends to create negative impact for the replenishment of the upper unconfined aquifer in the studied area. Study showed that the March flows of Ganges River are as much as $57 \%$ lower than in the pre-Farakka days (Treadwell and Akanda 2009). Due to the significant withdrawal of water the 
downstream riparian country of Teesta barrage are going to be dried up. Karotoa, Fakirni, Buri Teesta, Sonavori, Fulkumar and few other smaller rivers and tributaries in this region are going to be dried up for the same reason (www.probenewsmagazine.com/index).
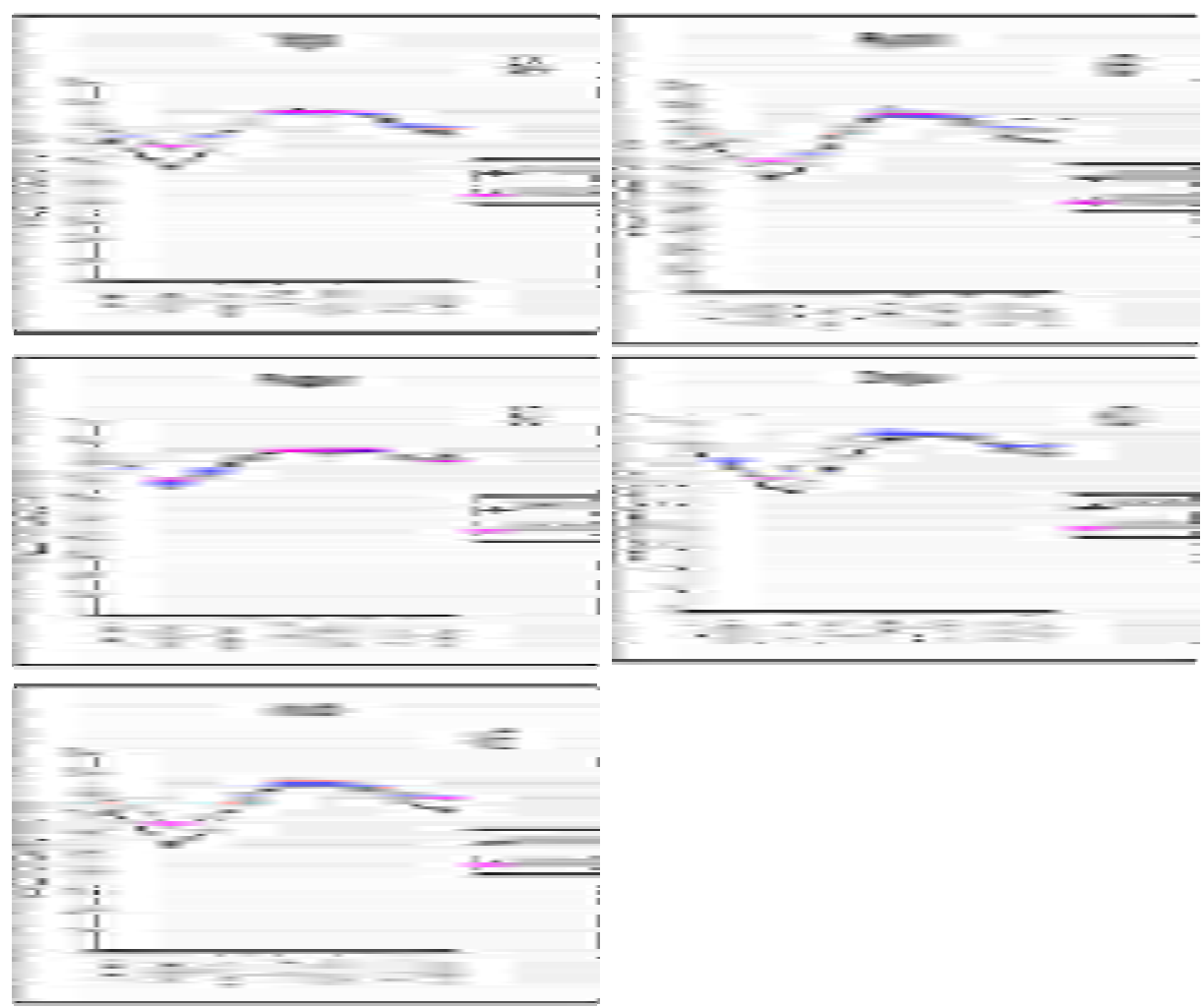

Fig. 6. Changes in mean monthly humidity at different stations - 6A: Bogra; 6B: Rajshahi; 6C: Rangpur;6D: Dinajpur and 6E: Ishurdi.

Long-term hydrographs from five surface water stations were used to determine the longterm variation of SWL at the selected rivers. No significant variations of SWL were observed in Deonair river at Bogra, Ghagoti river at Rangpur and the Korotia river at Dinajpur. Reduction of SWL was observed in Fakirni river at Rajshahi. Declination of SWL is more remarkable at Teesta river at Rangpur (Fig. 7). Both of these two rivers were influenced by the human intervention in the upstream countries.

At Bogra, Rajshahi and Dinajpur the peak of the mean SWL generally started in July during both of the intervals (1995 - 1999 and 2000 - 2004). But at Rangpur the peak of mean SWL started in July during the first half but later the peak shifted to June. 

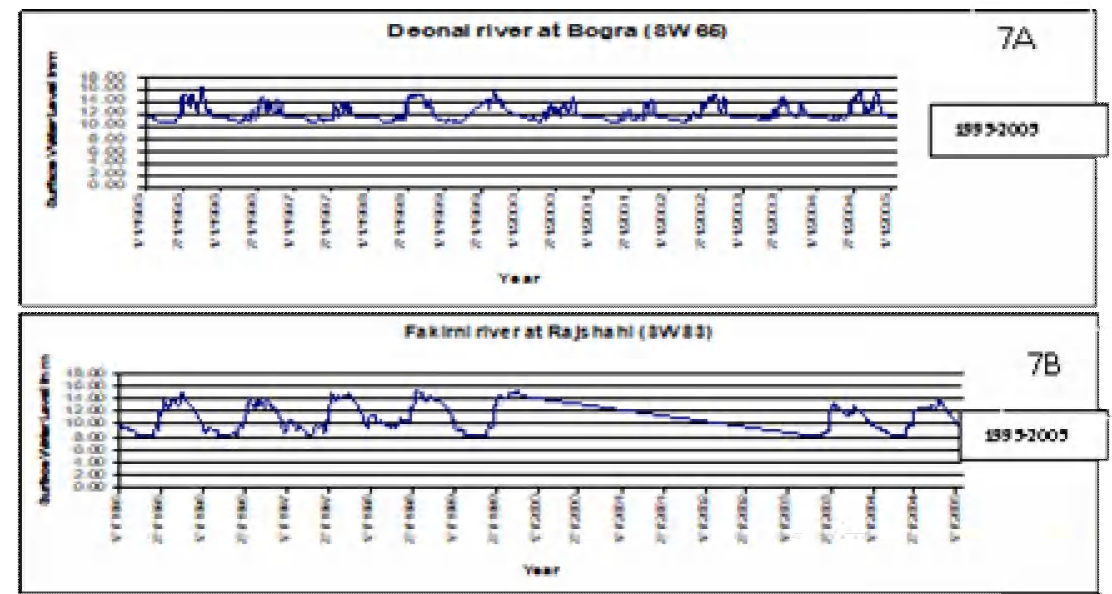

ver
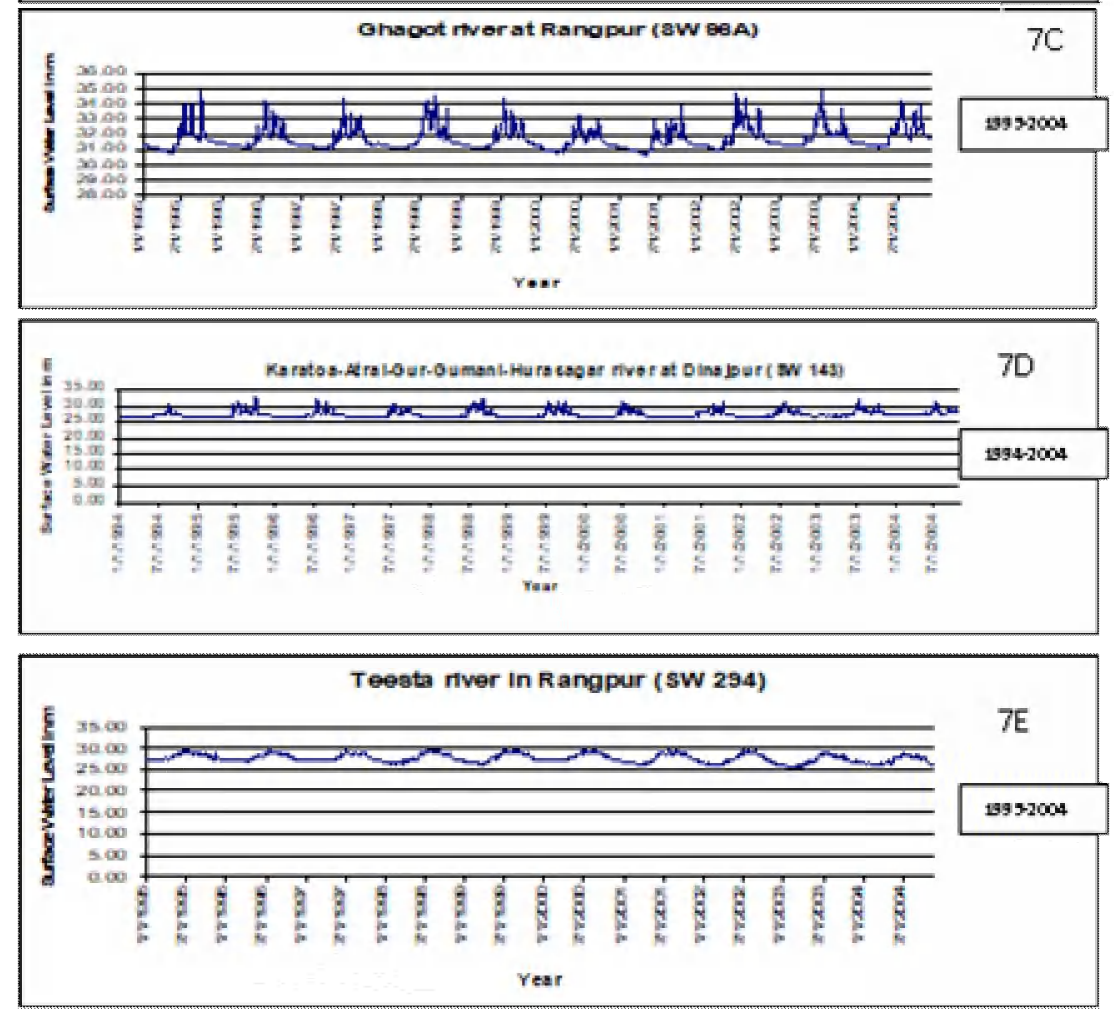

Fig. 7. Long-term changes of surface water level at different rivers in the study area - 7A: Deonair river at Bogra; 7B: Fakirni river at Rajshahi; 7C: Ghagoti river at Rangpur; 7D: Karatoa river at Dinajpur and 7E: Teesta river at Rangpur (Source: BWDB). 
Correlating with the rainfall intensity during different months it was found that everywhere the peak of the mean SWL was following the peak of monsoon rainfall. Both of the mean maximum and minimum SWL at station SW 83 in Rajshahi and SW 294 in Rangpur decreased throughout the year. At SW 96 in Rangpur, the mean SWL slightly increased in summer and monsoon months but decreased during the winter. However, the mean SWL slightly decreased during the monsoon but slightly increased during the winter and summer period at SW 65 in Bogra. At SW 143 in Dinajpur, both the mean maximum and minimum SWL increased throughout the year (Table 3).

Table 3. Mean monthly maximum and minimum SWL in $\mathrm{m}$ at different year range.

\begin{tabular}{|c|c|c|c|c|c|}
\hline \multirow{3}{*}{$\begin{array}{l}\text { Station } \\
\text { name }\end{array}$} & \multirow{3}{*}{ Location } & \multicolumn{4}{|c|}{ Ranges of mean monthly SWL (m) } \\
\hline & & \multicolumn{2}{|c|}{ 1995-1999 } & \multicolumn{2}{|c|}{ 2000-2004 } \\
\hline & & Max & Min & Max & Min \\
\hline SW 65 & Bogra & $11.09-15.186$ & $10.7875-12.83$ & $11.38-14.48$ & $10.97-12.8$ \\
\hline SW 83 & Rajshahi & $8.8-14.592$ & $8.388-13.7$ & $8.36-13.425$ & $8.175-12.36$ \\
\hline SW 96 & Rangpur & $31.1-33.7$ & $30.97-31.93$ & $31.16-34.19$ & $31.02-31.95$ \\
\hline SW 143 & Dinajpur & $26.59-31.56$ & $26.52-27.62$ & $26.82-30.91$ & $26.73-27.87$ \\
\hline SW 294 & Rangpur & $27.16-29.78$ & $26.7675-28.7$ & $26.5-29.5$ & $26.202-28.5$ \\
\hline
\end{tabular}

(Source: BWDB).

At SW 65 in Bogra, the mean minimum SWL was found in April during the two intervals (1995 - 1999 and 2000 - 2004). The mean maximum SWL during the first interval was found in September but in second interval it shifted to October. On the other hand, the mean maximum SWL was found in October for both intervals but the mean minimum SWL shifted from April to May at SW 83 in Rajshahi. Negligible seasonal shifting of mean maximum and minimum SWL was observed at SW 96 and SW 294 in Rangpur and SW 143 in Dinajpur. So, overall seasonal changes of the availability of surface water might negatively affect the seasonal irrigation water requirements in the NWPB.

Ground water level (GWL): According to UNDP (1982), the studied areas were categorized as zone A, D, E and F for groundwater development. Dinajpur district i.e. zone $\mathrm{D}$ is characterized by the sediments of mostly coarse detrital piedmont deposits. The clay and silt layers overlying the permeable surface sediment is thin enough to allow maximum infiltration of rainfall. Rangpur district i.e zone A consists mostly of coarse sediments which has the highest transmissivity in the country. The southern districts of the studied area i.e Bogra, Rajshahi and Ishurdi fall in mostly zone E and F, which consists of comparatively thicker layers of overlying clay and silt deposits. As a result, 
the rate of infiltration is relatively lower in the southern districts of NWPB (UNDP 1982).

The highest mean monthly GWL was found at DIO-25 in Dinajpur which was $35.72 \mathrm{~m}$ and the lowest was found at Rajshahi in RJ-029 which was $5.02 \mathrm{~m}$ during the period 1995 - 1999. During the year range 2003 - 2007, highest GWL $36.07 \mathrm{~m}$ was observed at the same station of Dinajpurand the lowest $5.82 \mathrm{~m}$ in RJ-029 at Rajshahi. Mean monthly GWL showed that its elevation decreased during the second interval (2003 - 2007) throughout the year at B-067, but slight fall was observed at Bogra in B-030, B-009 and B-028. On the other hand, DIO-067 at Dinajpur showed continuously decreasing pattern throughout the year and DIO-025 showed significant reduction during winter and summer but increased higher during monsoon than the past. At both of the stations of Rajshahi, GWL elevation was very low. GWL at RJ-032 was continuously declining but at RJ-029 GWL increased from October to March. GWL was continuously declining throughout the year except the months between April and July at RA-31. No shifting of maximum and minimum GWL was observed in B-028, DIO-025 and RJ-029. At B-03, DIO-067 and RA-031 the minimum GWL was found in April but in all stations maximum GWL shifted from September to October at the second interval. At B-9, minimum GWL shifted from April to March and maximum GWL from November to October. At RJ-32, mean minimum GWL shifted from June to May (Table 4).

Table 4. Mean monthly maximum and minimum GWL in different periods.

\begin{tabular}{|c|c|c|c|c|c|}
\hline \multirow{3}{*}{$\begin{array}{l}\text { Station } \\
\text { name }\end{array}$} & \multirow{3}{*}{ Location } & \multicolumn{4}{|c|}{ Ranges of mean monthly GWL (m) } \\
\hline & & \multicolumn{2}{|c|}{ 1995-1999 } & \multicolumn{2}{|c|}{$2000-2004$} \\
\hline & & $\operatorname{Max}$ & Min & Max & Min \\
\hline B-030 & Bogra & $6.78-9.4$ & $6.56-8.72$ & $6.84-8.81$ & $6.58-8.4$ \\
\hline B-003 & Bogra & $13.04-18.36$ & $12.34-17.61$ & $14.05-18.1$ & $13.17-16.85$ \\
\hline B-028 & Bogra & $10.03-13.94$ & $9.76-13.08$ & $10.44-13.67$ & $10.17-12.26$ \\
\hline B-009 & Bogra & $8.97-12.99$ & $8.23-12.38$ & $9.72-14.14$ & $8.84-13.43$ \\
\hline DIO-25 & Dinajpur & $33.43-35.72$ & $32.87-35.41$ & $31.48-36.07$ & $30.99-35.76$ \\
\hline DIO-67 & Dinajpur & $26.51-29.48$ & $27.76-30.02$ & $25.18-29.25$ & $25.59-29.94$ \\
\hline RJ-029 & Rajshahi & $6.29-13.1$ & $5.02-12.22$ & $6.11-13.4$ & $5.82-13.16$ \\
\hline RJ-032 & Rajshahi & $9.8-11.76$ & $9.62-11.63$ & $8.98-10.5$ & $8.48-10.05$ \\
\hline RA-31 & Rangpur & $28.9-31.44$ & $28.57-30.54$ & $28.94-31.03$ & $28.64-30.3$ \\
\hline
\end{tabular}

(Source: BWDB). 


\section{Conclusion}

Significant variation in temperature, atmospheric humidity, evaporation rate and wind speed were observed during different seasons in the NWPB. Increased rainfall in monsoon period and contemporaneous decrease in dry period might aggravate the flood condition during monsoon and drought during the winter period. More changing trend of rainfall pattern than the previous time clearly indicates the changes of climatic condition. Higher annual variability along with unpredictable rainfall shifting than the past might be a reason for the seasonal droughts which badly affect the agricultural production in the NWPB. Comparatively higher AI values during monsoon and lower values during the other seasons than the past shows the higher possibility of flood during the wet monsoon season and drought condition during the dry periods. Remarkable reduction of SWL at Teesta river in Rangpur and also at the Fakirni river in Rajshahi throughout the year was observed. Decrease in SWL and seasonal shifting of peaks may badly affect the agricultural practice. Seasonal shifting of mean maximum GWL at most of the stations with continuous declining of GWL in a few other stations increases the possibility of drought. Finally, the changing pattern of the climatic condition in this study necessitates further vigorous research for better understanding the climatic status in the NWPB.

\section{Acknowledgement}

The authors are thankful to Bangladesh Meteorological Department (BMD) and Bangladesh Water Development Board (BWDB) for providing their valuable hydrometeorological data to carry out this research.

\section{References}

Ahmed, R. and I.K. Kim. 2003. Patterns of daily rainfall in Bangladesh during the summer monsoon season: Case studies at three stations. Physical Geography 24(4): 295-318.

Banglapedia, 2003. National Encyclopaedia of Bangladesh. Asiatic Society of Bangladesh, Dhaka.

Brammer, Hugh, 1996. The Geography of the Soils of Bangladesh. The University Press Limited, Dhaka. 287 p.

Christensen, J.H., B.Hewitson, A Busuioc, A. Chen, X. Gao, I. Held, R. Jones and R.K. Kolli, 2007. Regional Climate Projections. In: Climate Change 2007. The Physical Science Basis. Contribution of Working Group to the Fourth Assessment Report of the Intergovernmental Panel on Climate Change. Cambridge University Press, Cambridge, United Kingdom and New York, NY, USA.

Institute of Water and Flood Management (IWFM), Bangladesh University of Engineering and Technology (BUET), 2009. Characterizing Long term changes of Bangladesh climate in context of Agriculture and Irrigation. Climate change cell, DoE, MoEF, Component 4b, CDMP, MoFDM, Dhaka. 
Islam, Sirajul. 2003. Banglapedia. Asiatic Society of Bangladesh, Dhaka.

McIntosh, D.H. 1972. Meteorological glossary. Her Majesty's Stationery Office, Met. O. 842, A.P. 897. 319 p.

Rashid er, Haroun. 1991. Geography of Bangladesh. The University Press Limited, Dhaka. p. 529.

Shahid, S, X. Chen and M.K. Hazarika, 2005. Assessment aridity of Bangladesh using geographic information system. GIS Development. 9(12): 40-43.

Shamsuzzoha, M., Md. Zahurul Islam, Riaz Hossain Khan and M.N.Amin, 2011. Status of climatic variations in north western region of Bangladesh. Journal of Agroforestry and Environment. 5(2): 57-61.

Treadwell, J. and A.S. Akanda, 2009. Contributing Factors in the Ongoing Water Conflict Between Bangladesh and India. https://wikis.uit.tufts.edu/confluence/display/aquapedia. Retrieved on November 21, 2011.

Trewartha, Glenn T 1968. An Introduction to Climate. Mcgraw-hill Book Company, New York.

United Nations Development Program (UNDP), 1982. Groundwater survey, The Hydrogeologic conditions of Bangladesh. DP/UN/BGD-74-009/1, New York: p. 83-86. 